\title{
豕脊齿象属(Choerolophodon)头骨化石在中国的 发现
}

\author{
王世骐*，邓涛 \\ 中国科学院古脊椎动物与古人类研究所, 脊椎动物进化系统学重点实验室, 北京 100044 \\ *E-mail: wangshiqi@ivpp.ac.cn
}

收稿日期: 2010-07-05; 接受日期: 2010-12-09

中国科学院知识创新工程重要方向项目(编号: KZCX2-YW-Q09, KZCX2-YW-120)、国家自然科学基金(批准号: 40730210, 41002010)、国 家重点基础研究发展计划项目(编号: 2006CB806400)和中国科学院脊椎动物进化系统学重点实验室开放课题基金(编号: 2010LESV004)资助

\begin{abstract}
摘要在甘肃省临夏盆地大浪沟地点的早中新世地层中发现了一件较完整的豕脊齿象属 (Choerolophodon)头骨, 这是该属的头骨化石在中国的首次报道. 该头骨低平，门齿向外侧及上 方弯曲且没有釉质带, 臼齿为豕脊型齿, 因而符合豕脊齿象属的鉴定特征, 并与嵌齿象属 (Gomphotherium)、铲齿象属(Platybelodon)和中华乳齿象属(Sinomastodon)等中国常见的嵌齿象类 相区别; 同时具有以下一些相当原始的特征而不同于豕脊齿象属的其他种：颧弓明显向两侧扩 展、前眶位置靠前、项齿上白严质发育很弱、 $\mathrm{P} 4$ 仍然发育, 因此被确定为一新种一一广河豕脊 齿象(Choerolophodon guangheensis sp. nov.). 在本文的新材料发现之前, 豕脊齿象属的材料主要 发现于非洲、东欧、西亚和南亚的中中新世到晚中新世。新材料的发现，拓宽了对该类群时间和 空间分布的认识，对于研究嵌齿象类在东亚地区早中新世的分支演化和适应辐射提供了重要的 材料依据.
\end{abstract}

关键词

嵌齿象类 豕脊齿象属

临夏盆地 早中新世 中国
本文所讨论的嵌齿象类指的是嵌齿象科 (Gomphotheriidae Hay, 1922). 根据 Shoshani 和 Tassy $^{[1]}$ 的最新分类方案, 嵌齿象科大致相当于 Tobien $^{[2]}$ 所谓丘齿三棱乳齿象(bunodont trilophodont mastodont)的范围, 是长鼻目动物的主干类型. 嵌齿 象类起源于埃及法尤姆 (Fayûm) 渐新世的象型动物 (Elephantiformes Tassy, 1988, 包括 Palaeomastodon 和 Phiomia 等属 ${ }^{[1]}$ ), 在其演化的开始阶段, 嵌齿象类 便是一种体大厚重型的动物, 并且善于迁移奔走, 在 早中新世嵌齿象类便迁移到了欧亚大陆 ${ }^{[3]}$, 在中中新 世到达了美洲 ${ }^{[4]}$. 在其生存区域内, 嵌齿象类适应多
样化的生存环境, 发展出了大量的属种, 因此一直被 作为地层对比的标志性生物.

中国是嵌齿象类从非洲和欧亚大陆往美洲迁移 的过渡地带. 从中中新世开始, 中国的嵌齿象类化石 记录非常丰富; 然而在早中新世, 嵌齿象类的化石记 录非常稀少, 比较有代表性的如甘肃省肃北蒙古族 自治县早中新世铁匠沟组下部(约 19 20 Ma)发现的 党河铲齿象 (Platybelodon dangheensis $)^{[5,6]}$. 最近, 在 甘肃省临夏盆地早中新世晚期的上庄组也发现了嵌 齿象类化石, 其中有一件较完整的头骨经本文鉴定, 属于豕脊齿象属(Choerolophodon). 这个属与嵌齿象

英文引用格式: Wang S Q, Deng T. The first Choerolophodon (Proboscidea, Gomphotheriidae) skull from China. Sci China Earth Sci, 2011, doi: 10.1007/s11430-011-4201-6 
属(Gomphotherium)并非同一支系, 而是代表了嵌齿 象类的一个早期分支. 在中国, 此前仅有一些曾经被 归为嵌齿象属或铲齿象属的零星牙齿材料被 Tobien 等 ${ }^{[7]}$ 鉴定为豕脊齿象属未定种, 因此, 新材料的研究 对于深入认识嵌齿象类在中国的适应辐射有非常重 要的意义.

临夏盆地位于中国西部，青藏高原东北缘，其间 发育了从早渐新世到早更新世较为完整的地层沉积 序列. 嵌齿象类化石的出土地点位于广河县买家巷 乡东南, 广通河南岸的一个名为大浪沟的冲沟中 $\left(35^{\circ} 26^{\prime} 50.7^{\prime \prime} \mathrm{N}, 103^{\circ} 27^{\prime} 28.5^{\prime \prime} \mathrm{E}, 2060 \mathrm{~m}\right.$, 地点编号: LX200001, 图 1). 剖面从底到顶为早中新世上庄组、 中中新世东乡组和虎家梁组, 以及晚中新世柳树组, 上覆更新世马兰黄土. 其中上庄组是一套黄褐色钲 质胶结粉砂岩递变为红褐色粉砂质泥岩的地层, 在 其上部的砾岩透镜体中含有本文记述的材料. 由于 在广通河北岸寺沟地点的上庄组地层中发现了早中 新世的小哺乳动物群, 包括 Mioechinus sp., Amphichinus sp., Sinolagomys ulunguensis, Atlantoxerus sp., Paracricetulus? sp., Heterosminthus sp., Protalactaga sp., Litodonomys sp., Sayimys sp.和 Tachyoryctoides sp., 因此, 将大浪沟化石地点的时代估计为早中新世晚
期.

嵌齿象类头骨的测量以及项齿表面构造的描述 依照 Tassy ${ }^{[8]}$ 文章中的图 4 和 5(附图 1 和 2, 见网络版 http://earth.scichina.com).

研究单位简写: GM-Vm, 中国地质博物馆标本 编号; HMV, 甘肃省和政古动物化石博物馆标本编号; IVPP $\mathrm{V}$, 中国科学院古脊椎动物与古人类研究所标 本编号; TM，天津自然博物馆标本编号.

\section{1 系统记述}

长鼻目 Proboscidea Illiger, 1811

嵌齿象科 Gomphotheriidae Hay, 1922

豕脊齿象亚科 Choerolophodontinae Gaziry, 1976

豕脊齿象属 Choerolophodon Schlesinger, 1917

广河豕脊齿象(新种) Choerolophodon guangheensis sp. nov.

图 2 6, 表 1 和 2

正型标本：IVPP V17685, 较完整的头骨, 带有 完整的左右 $\mathrm{I} 2$ 和 $\mathrm{P} 4 \sim \mathrm{M} 3$ 齿列.

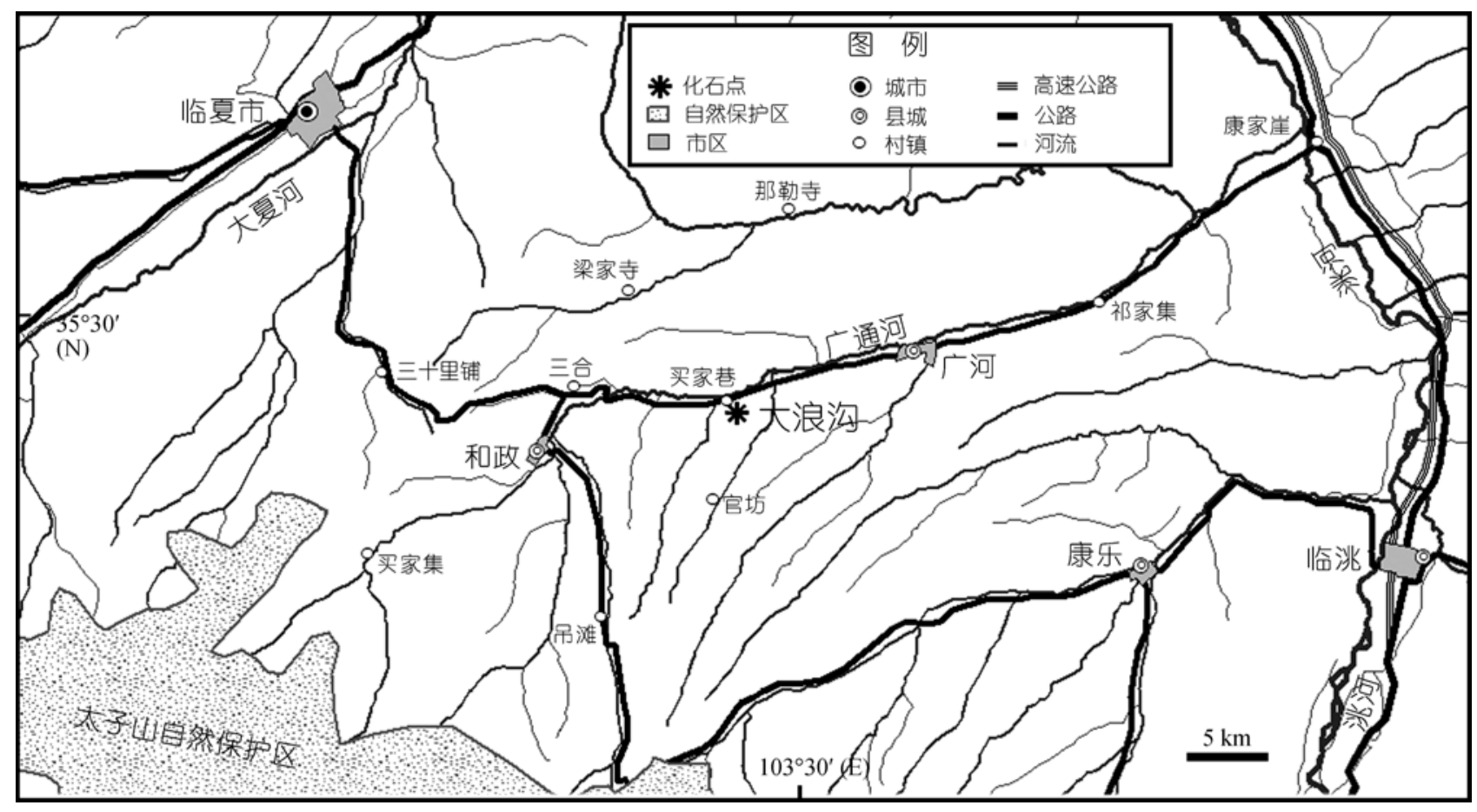

图 1 大浪沟化石点交通位置图 

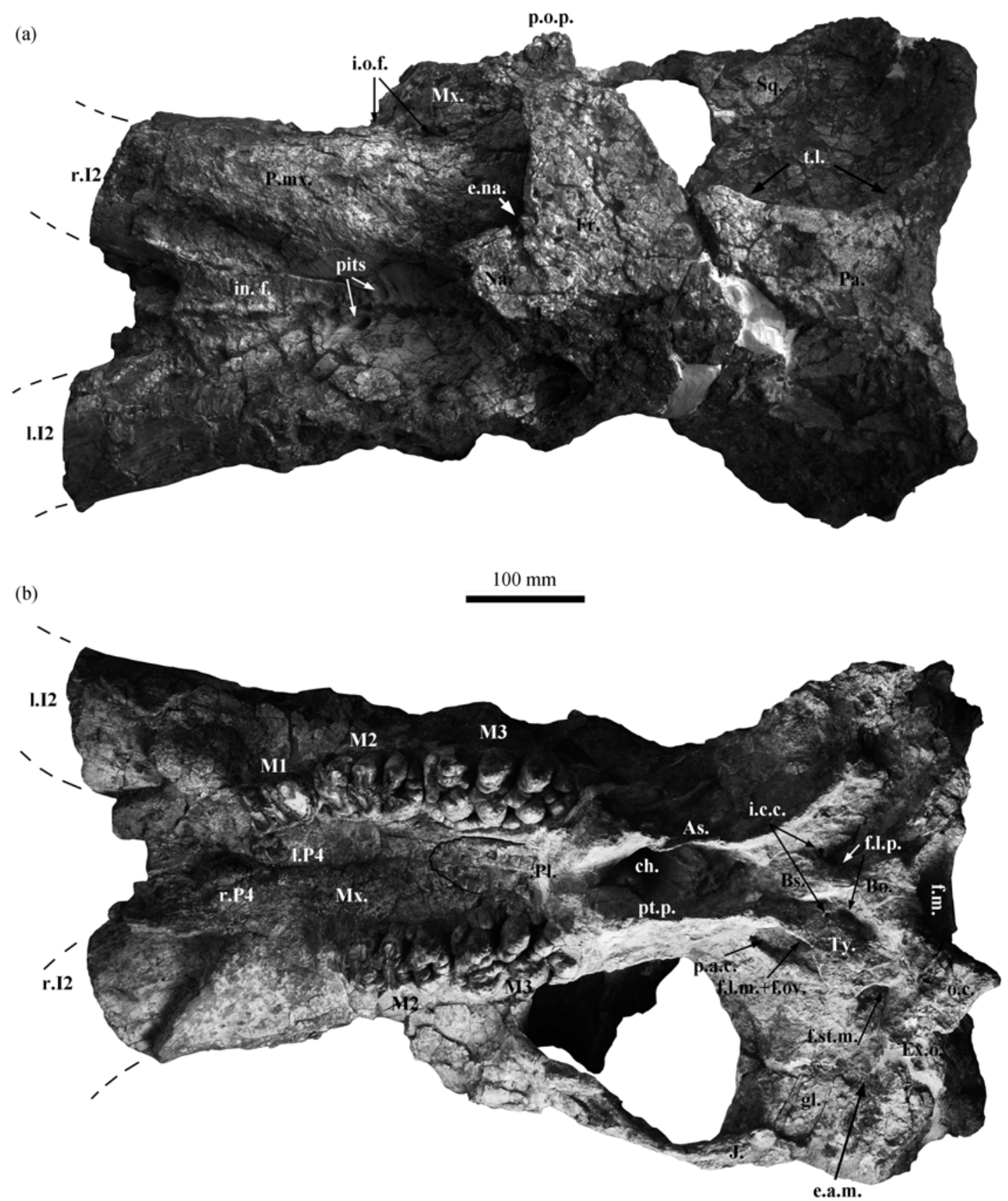

图 2 广河豕脊齿象(新种)头骨(IVPP V17685)

(a) 背面视; (b) 腹面视. 注释: As., 翼蝶骨; Bo., 基枕骨; Bs., 基蝶骨; ch., 内鼻孔; e.a.m., (次生的)外耳道; e.na., 外鼻孔; Ex.o., 外枕骨; f.l.m., 中裂孔; f.l.p., 后裂孔; f.m., 枕大孔; f.ov., 卵圆孔; f.st.m., 茎乳孔; Fr., 额骨; gl., 关节窝; i.c.c., 内颈动脉孔; i.o.f., 眶下孔; in.f., 门齿 窝; J., 歡骨; 1.I2, 左侧第二门齿; 1.P4, 左侧第四前白齿; M1, 第一白齿; M2, 第二白齿; M3, 第三白齿; Mx., 上领骨; Na., 鼻骨; o.c., 枕髁; p.a.c., 翼管后口; P.mx., 前领骨; p.o.p., 眶后突; Pa, 顶骨; Pl., 腭骨; pt.p., 翼突; r.I2, 右侧第二门齿; r.P4, 右侧第四前白齿; Sq., 鳞骨; t.1., 颢线; Ty., 听泡

其他标本: IVPP V17686, 左侧 M2?第三脊及跟座残 段; HMV1774, 右侧? I2 中段; HMV1775, 4 段 I2 残段, 属于同一个化石块; HMV1776, 左侧 I2 后段;
HMV1777，完整的左侧 I2；HMV1778，右侧 I2 中段; HMV1779, 完整的左侧 I2; HMV1780, 右侧 I2 后段; HMV 1822, 右侧? I2 前段; HMV1823, 右侧 I2; 
表 1 广河豕脊齿象(新种)头骨(IVPP V17685)测量 ${ }^{\text {a) }}$

\begin{tabular}{|c|c|c|c|c|c|c|c|c|c|}
\hline 测量项 & 1 & 2 & 3 & 4 & 5 & 6 & 7 & 8 & 9 \\
\hline 头骨 & 765 & 398 & 395 & 368 & 63 & 428 & 316(ca.) & 352 & 74 \\
\hline 测量项 & 10 & 11 & 12 & 13 & 14 & 15 & 16 & 17 & 18 \\
\hline 头骨 & 270 (ca.) & 94 & 777 & 345 & 192 & 310 & 273 & 115 & 580 \\
\hline 测量项 & 19 & 20 & 21 & 22 & 23 & 24 & 25 & 26 & 27 \\
\hline 头骨 & 476 & 63 & 87 & 211 & 84 & 125 & 175 & 570 (ca.) & 90 (ca.) \\
\hline 测量项 & 28 & 29 & 30 & 31 & 32 & 33 & 34 & 35 & 36 \\
\hline 头骨 & - & 45 & 96 & 234(ca.) & 468 & 292 & 249 & 329 & 176 \\
\hline
\end{tabular}

a) 测量项依照 $\mathrm{Tassy}^{[8]}$ 中的图 5: 1, 从枕骨边测量的最大长度; 2 , 脑颖长度; 3 , 前领骨长度; 4 , 门齿窝长度; 5 , 鼻骨长度; 6 , 最大睈上 宽度; 7, 吻部后宽(在下眶下孔间测量); 8, 吻部前宽; 9, 鼻骨宽度; 10, 外鼻孔宽度; 11, 脑频题线间最小宽度; 12, 从枕髅测量的最大长度; 13, 颧弓长度 (从上领颧突前到关节窝后缘); 14 , 从颧弓水平面上测量颢窝长度; 15, 硬腭长度(从第一个顿齿到内鼻孔); 16, 内鼻孔到枕大孔 的长度; 17 , 上领骨歡突厚度; 18 , 脑颎最大宽度(从两㩲弓上测量); 19 , 硕基宽度(从两关节窝的外缘测量); 20 , 内鼻孔最大宽度; 21 , 硬腭内 部最大宽度; 22 , 硬腭外部最大宽度; 23 , 硬腭内部在第一軑齿前端的宽度; 24 , 硬腭最小宽度, 在内齿槽脊(上领脊)间测量; 25 , 枕骨矢向高 度; 26, 枕骨宽度; 27, 前领骨高度, 28, 面部高度(在第一䒜齿前端测量); 29, 上领在颧突之下的高度; 30, 眼眶高度; 31, 脑峒高度(从硕顶到 翼突); 32, 颅基长度(从翼突到枕髁); 33, 面部长(从吻部前端到翼突); 34 , 眶题窝长(从鳞骨前缘到眼眶前缘); 35 , 颅中部长(从眼眭下缘到外 耳道开口); 36, 顽中部高(从翼突到眼眭背缘); ca, 估计值. 单位: mm

表 2 广河豕脊齿象(新种)正型标本(IVPP V17685)牙齿测量 ${ }^{\text {a) }}$

\begin{tabular}{|c|c|c|c|c|c|c|c|c|}
\hline & 长度 $(\mathrm{mm})$ & 宽度 $(\mathrm{mm})$ & 高度(mm) & $\mathrm{L} 1$ & L2 & L3 & 跟座宽度 $(\mathrm{mm})$ & $I$ \\
\hline I2 1. & $1115^{*}$ & - & $94.5^{* *}$ & & & & & \\
\hline $\mathrm{I} 2 \mathrm{r}$. & $1018^{*}$ & $120^{* *}$ & $96^{* *}$ & & & & & \\
\hline P4 1. & 37 & 24 & - & & & & & 64.9 \\
\hline P4 r. & 40 & - & 14 & & & & & - \\
\hline M1 1. & $72+$ & 49 & - & 44 & 49 & 48 & & - \\
\hline M2 1. & 97 & 60 & - & 57 & 60 & 60 & & 61.9 \\
\hline M2 r. & 103 & 63.5 & - & 63.5 & 62.5 & 60 & & 61.7 \\
\hline M3 1. & 134 & 74 & $51^{* * *}$ & 74 & 71 & 61 & 43 & 55.2 \\
\hline M3 r. & $130+$ & 79 & $52.5^{* * * *}$ & 79 & - & - & - & - \\
\hline
\end{tabular}

a) L1, 第一脊宽度; L2, 第二脊宽度; L3, 第三脊宽度; 单位: $\mathrm{mm} . I=$ 宽度 $\times 100 /$ 长度; 1. , 左侧; r., 右侧. ${ }^{*}$ 门齿尖端到齿槽前端的长度; ${ }^{* *}$ 在齿槽前端测量; ${ }^{* * *}$ 在第一脊副齿柱外侧测量

HMV1816-1 和 HMV1816-2, 左侧 I2 两根; HMV1817, 未经修理的含化石大岩块, 其中至少有 4 段属于该种 的 I 2 .

种名来源: 以化石产地所在的县命名.

特征: 个体较小的豕脊齿象. 颖部及面部低平, 均前后延伸; 前领骨特别长, 门齿窝后缘的凸棱在鼻 骨前端靠后的位置(深入外鼻孔中); 颢线在频顶部的 间距较 Choerolophodon pentelici 的窄, 而较 Afrochoerodon chioticus 的宽, 颅顶部后缘中凹; 㩲弓及颖底 部向两侧膨大, 歡骨的后端达到了关节窝外侧的前 端; 硬腭的后缘在齿列之后, 颖基部(翼突后部)与腭 部(翼突前部)几乎位于同一平面内; 成年个体中眼眭 前缘位于 $\mathrm{M} 2$ 第三脊处的上方. 上门齿异常粗长, 截 面为圆形或栯圆形，从齿槽基部向外分开，在前端向 上弯, 没有釉质带发育. P4 保存但很弱小, 并且与
$\mathrm{M} 1, \mathrm{M} 2$ 和 M3 同时存在; 中间上颊齿为三脊型, M3 呈三角形, 3.5 脊; 整个臼齿呈现出较明显的“豕脊型 齿 (choerolophodonty)” 及较弱的 “褶型齿 (ptychodonty)”, 白严质发育很弱.

描述：头骨(图 2 4)：正型标本(IVPP V17685)风 化严重, 表面呈鳞片状剥落.

背视(图 2(a)): 面部及妙部均窄长. 左侧顶额部 破损，歡部缺失.

前领骨宽大且长，向前水平伸出. 左右前领骨间 的门齿窝很发达, 其后端膨大, 中部形成一个窄小的 颈部，在前端渐渐变得宽阔; 门齿窝后缘的凸棱在鼻 骨前端的后方, 深入外鼻孔内部; 门齿窝中部两侧各 有 5 6 道粗糙的凹窝以附着发达的领唇肌. 门齿槽的 外鞘异常粗壮, 向外侧分开, 角度约 $25^{\circ}$. 鼻骨前端 成一个大而尖的三角形向前方突出, 尖端略有损坏. 


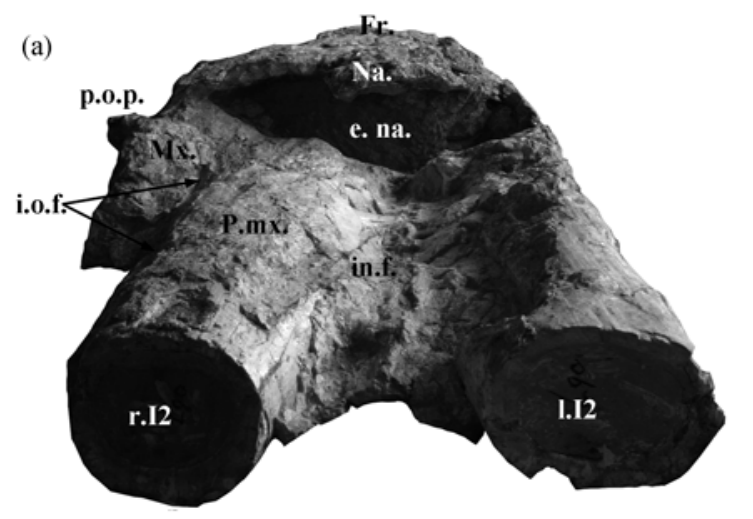

(b)

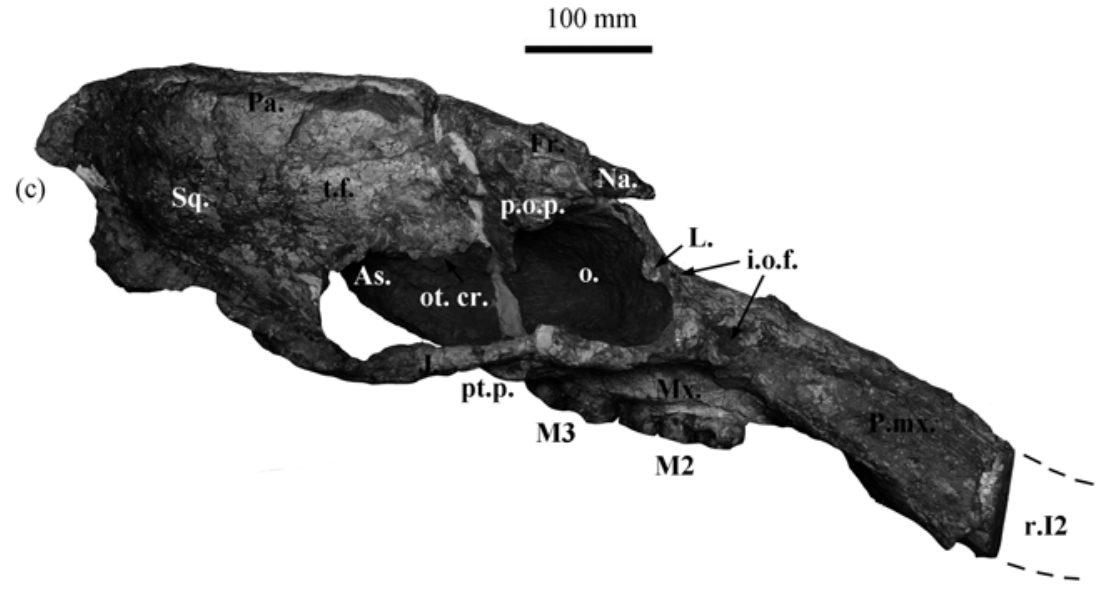

图 3 广河豕脊齿象(新种)头骨(IVPP V17685)

(a) 前面视; (b) 后面视; (c) 侧面视. L., 泪骨; 1.n.f., 项韧带窝; o., 眼眀; ot.cr., 眶额嵴; t.f., 题窝; 其余缩写同图 2

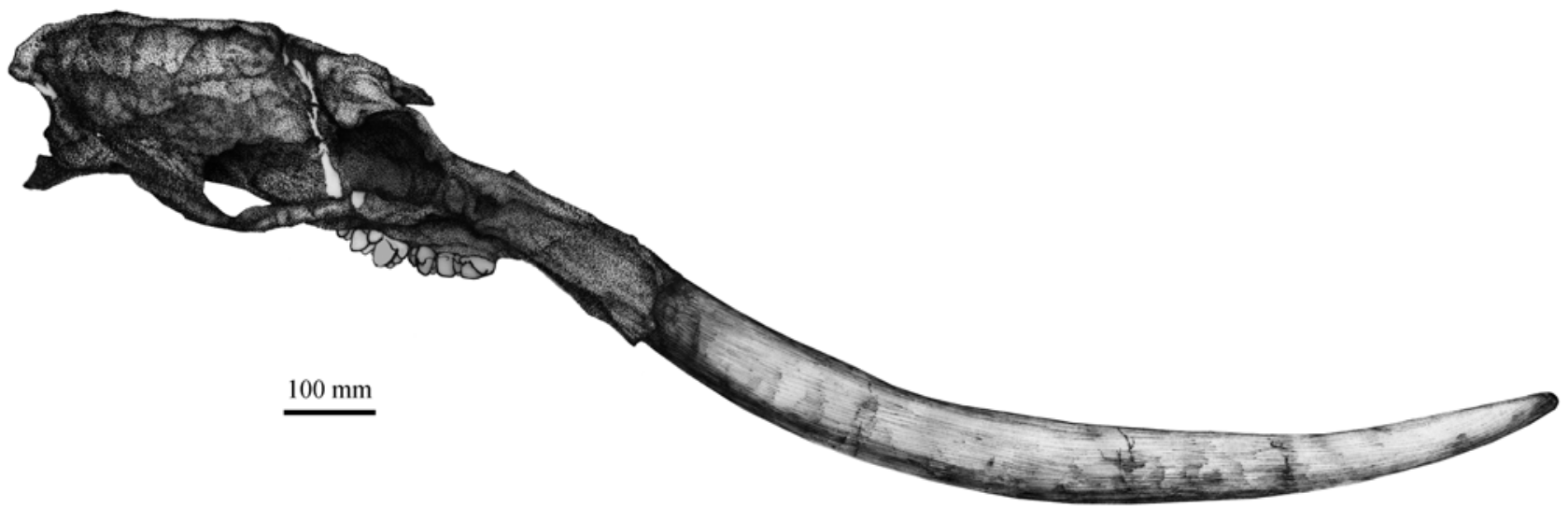

图 4 广河豕脊齿象(新种)头骨及门齿(IVPP V17685)侧视全形素描

额骨的顶面宽阔. 颠线在前方与睈后突相接; 中部向 中轴弯曲; 但在顶骨的顶面外侧基本平行于中轴, 使 得脑颖的顶面呈前后延长的方形; 颢线后部向外侧 延伸与枕嵴合并; 颢线在脑颖顶面的间距较
Choerolophodon pentelici 的窄, 而较 Afrochoerodon chioticus 的宽. 脑颅后缘明显中凹; 顶骨及鳞骨的颢 部明显向外侧扩展.

腹视(图 2(b)): 枆底部左侧外缘破损, 歡部缺失. 
门齿槽外鞘的底面形成一大的三角形切迹; 两 齿列间的硬腭部较窄, 中部略向上凹陷; 颧突形成一 个宽阔的板状结构, 水平向外突出并向后延伸; 表面 略向上凹陷. 颧弓细且向两侧膨大. 腭骨为长三角形, 与上领骨腭部的骨缝清晰; 其尖端位于 M2 与 M3 的 交界处; 其后缘向内鼻孔形成一个斜面.

内鼻孔前部呈椭圆形. 外侧的翼蝶骨与内侧的 翼骨共同包裹了上领骨后部的上领突; 翼突部位较 钝, 其前的腭部与其后的硕基部的夹角约为 $170^{\circ}$, 两 者接近位于同一平面上; 翼蝶骨后部近中处有大而 椭圆的翼蝶管后口.

翼突的锐缘向后方外侧延伸, 形成听泡前缘的 嵴, 此嵴的下方形成一道深沟, 其中为卵圆孔和中裂 孔的共同开口. 听泡呈向斜后方延伸的长方形; 内颈 动脉孔为小圆形, 位于听泡内侧, 开口在鼓骨上; 后 裂孔位于听泡后方内侧的大凹陷处; 听泡外侧后方 形成一个坚直的内凹小面; 茎乳孔在此面外侧的深 凹中.

鳞骨向外侧伸展, 相当宽大, 其下表面前部形成 一向前上方升起的平面; 中部的关节窝较平, 没有明 显的关节后突，歡骨的后端达到关节窝外侧的前端; 鳞骨下表面后部向上凹陷, 为次生的外耳道. 鳞骨后 方的外枕骨向外侧斜前方强烈突出形成一道凸棱.

枕髁仅保留右侧, 呈粗壮的三角形, 向后并强烈 向外侧延伸; 枕大孔横向扁平. 基枕骨在后端形成一 个很宽阔低平的三角形, 向前迅速收缩并抬升, 形成 一个短粗的圆柱形骨体, 在此骨体前又迅速向下变 低平, 形成一个粗糙面与前方的基蝶骨相接; 前蝶骨 与犁骨伸入内鼻孔中, 已被压损.

前视(图 3(a)): 外鼻孔较宽而低, 呈横向扁长的 椭圆; 右侧眼眀向外突出; 发达的齿槽外鞘占据了面 部的大部分.

后视(图 3(b)): 枕面非常宽阔, 并且与头骨的背 面和腹面接近垂直. 项韧带窝异常宽大(宽 $155 \mathrm{~mm}$, 高 $120 \mathrm{~mm}$ )且深, 显然是为了适应巨大的头骨及十分 粗壮的门齿; 其位于枕面正中, 上缘平下缘凹, 中嵴 很细.

侧视(图 3(c)和 4): 面部及颅部均长且相当低平, 略呈拱形, 额骨与顶骨的交界处约为最高点.

前领骨的齿槽外鞘很长, 强烈向前延伸, 前部较 粗, 后部稍细; 上领骨的外侧面低长. 鼻骨前端向前 尖出, 外鼻孔的上缘位于眼眀中部正上方.
眼眶较大, 前缘约位于 M2 的第三脊处上方; 前 缘中部有一小的泪突, 其下有一小切迹. 眭下孔的下 孔较大, 位于上领骨颧突的正前方; 上孔细长, 位于 眼睈前方背侧; 由于周围的上领骨较破碎, 两眭下孔 的形状较不规则. 眶后突较粗壮; 眶题崉从其下斜向 下后方延伸, 在下部形成了翼蝶骨的前缘覆盖在上 领骨之上.

暯窝呈前后方向非常宽大的扇形. 歡骨很细.

门齿(图 4 和 5): 异常粗壮, 表面没有任何釉质 带的痕迹. 正型标本的门齿在近端向两侧外分，远端 向内侧略呈弧形收缩, 并且明显向上方弯曲(图 4, 5(a) 和(b)), 但上弯程度弱于 Choerolophodon pentelici 和 Ch. corrugatus. 右侧门齿在齿槽处的截面为横向的 椭圆, 背侧较平, 腹侧弧度较大(图 5(c)); 在中段截 面变成接近圆形(图 5(d)和(e)); 在远端截面又变成粗 圆, 腹侧较平, 背侧弧度变大(图 5(f)). 除了正形标本, 其他归入此种的门齿或门齿残段中, 最粗的一根 (HMV1816-2)的截面长轴达到了 $143 \mathrm{~mm}$, 短轴达到 $105 \mathrm{~mm}$; 修复可靠的最长的一根(HMV1779)从根部 到尖端的直线长度达到了 $1245 \mathrm{~mm}$.

颊齿(图 6): 颊齿列非常独特. 左侧的 P4 M3 都 存在, 右侧的 M1 已经脱落(左侧 M1 也行将脱落), 但 右侧的 P4 仍然存在; 两侧的 P4 位置不对称, 左侧 P4 位于 $\mathrm{M} 1$ 的内侧, 几乎与 $\mathrm{M} 1$ 横向并列, $\mathrm{M} 1$ 的前缘在 $\mathrm{P} 4$ 的中部位置; 右侧 P4 整体上位于左侧 P4 之前, 其 后缘位于左侧 P4 前缘, 冠面的方向也向腭部中矢面 内侧旋转. P4 很小, 齿冠很低, 完全没有磨耗, 冠面 略呈椭圆形, 由两个齿脊及一个后跟座组成. 第一脊 主齿柱与副齿柱界限不清, 表面为白严质覆盖; 第二 脊主齿柱和副齿柱均分裂为两个乳突; 跟座为两个 小的乳突在后方排列. 齿带几乎不发育. P4 的发育情 况表明 P4 已经相当退化.

右侧 M1 已脱落. 左侧 M1 也行将脱落, 可见齿 根; 表面磨耗严重, 第三脊反而比前两脊磨耗严重, 可能是由于在生长过程中, 后边的 M2 不断向前挤压, 使得 M1 的后部抬升，从而使 M1 后部的磨耗比前部 严重. 此现象在非洲始轭齿象属(Eozygodon)中出现 过 ${ }^{[9]}$, 可能是象类出齿方式尚未完全达到水平替换的 一种进化中间阶段. M1 呈长方形, 由三脊组成. 第一 脊主齿柱磨耗后形成向前方近轴侧倾斜的三叶形图 案, 三叶的中叶与前叶有愈合的趋势; 副齿柱磨耗后 形成横长的扁圆形图案, 垂直于 M1 中轴, 副齿柱后 


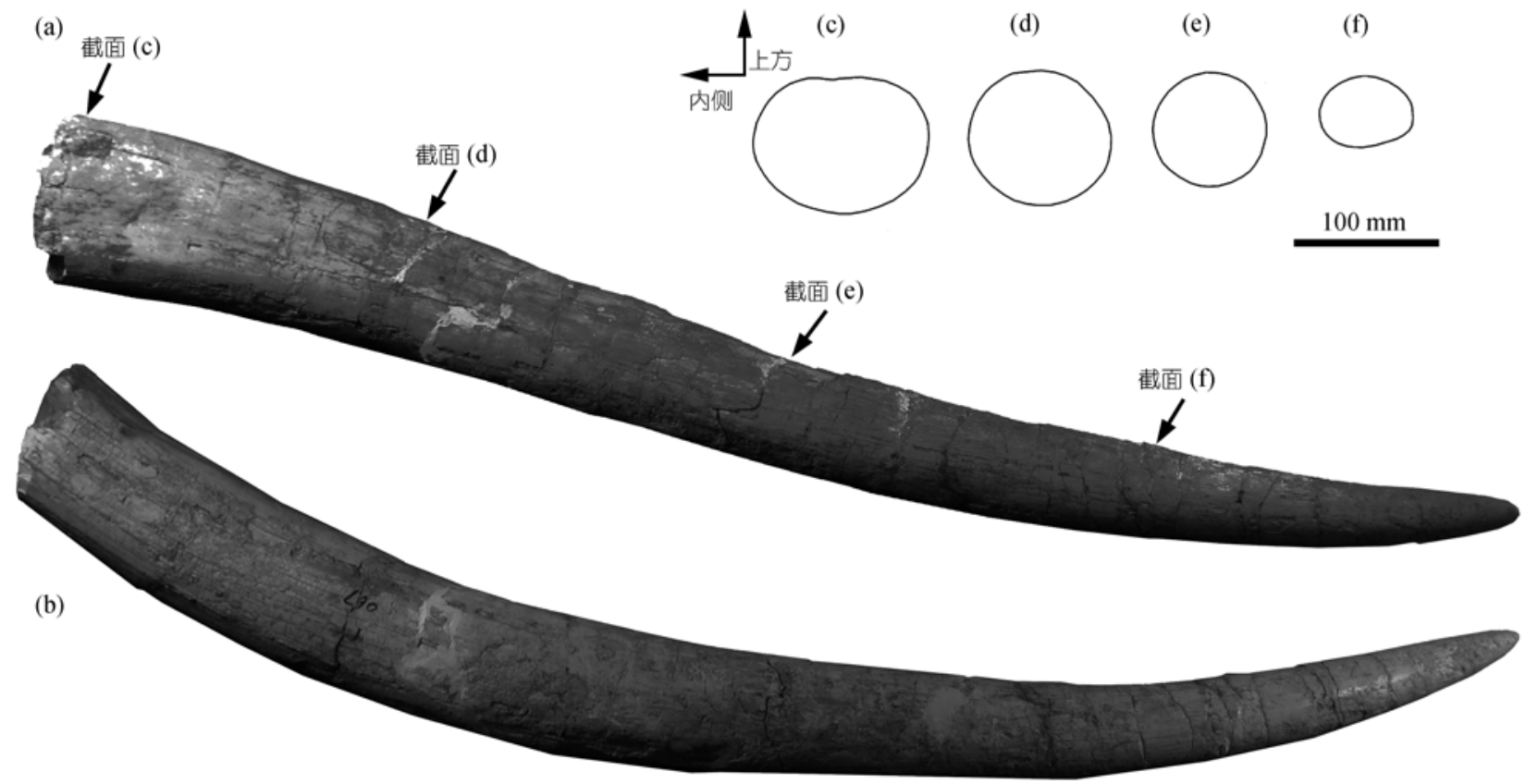

图 5 广河豕脊齿象(新种)正型标本(IVPP V17685)右侧上门齿

(a) 背侧视; (b) 外侧视; (c) (f) 分别为齿槽未端(距尖端 $1018 \mathrm{~mm}$ )截面(c)及从门齿尖端向根部 $750 \mathrm{~mm}$ (d), $500 \mathrm{~mm}$ (e)和 $250 \mathrm{~mm}$ (f)截面后视 的外轮廓

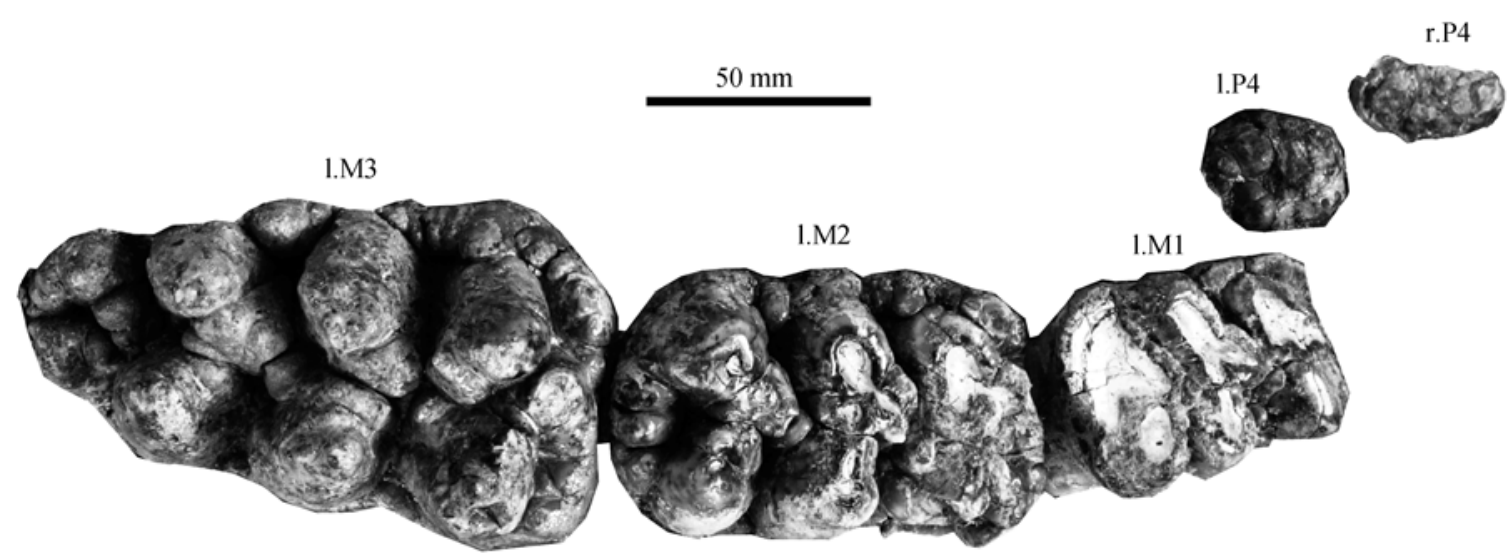

图 6 广河豕脊齿象(新种)正型标本(IVPP V17685)左侧 P4 M3 颊齿列及右侧 P4

侧近轴处有后中心小尖发育，后壁的釉质层强烈褶 曲, 唇侧齿谷中及边缘有一个粗壮的乳突及一些稍 小的乳突发育. 第二脊与第一脊类似, 主齿柱磨耗的 三叶图案的中叶与前叶完全愈合, 而且更加向前方 近轴侧倾斜; 副齿柱的磨耗图案也略向前方近轴侧 倾斜, 有中附锥及后中心小尖发育, 后壁的釉质层也 发育了褶曲. 第三脊主齿柱已磨耗到根部, 磨耗图案 的前方紧贴着第二脊主齿柱后壁, 后方与跟座的磨
耗图案连通，形成一个近轴边不规则的直角扇形的 图案; 副齿柱磨耗图案为椭圆形, 略向前方近轴侧倾 斜. 齿带在前端(虽已破损)及第一脊舌侧发育, 其余 部分发育很弱; 白严质发育很弱.

左侧 M2 呈长方形, 后缘较圆, 由三脊及一跟座 组成. 第一脊磨耗中等, 最后一脊刚开始磨耗, 后两 脊多少呈尖点向前的 $\mathrm{V}$ 形, 整个冠面呈现出较为明 显的豕脊型齿和较弱的褶型齿. 第一脊主齿柱磨耗 
后形成不规则的形状, 但仔细辨认发现其仍然是非 典型的三叶形: 第一脊主齿柱的前中心小尖与前方 齿带相连, 中附雉的磨耗图案并非与主尖连通, 而是 与前中心小尖连通, 说明中附雉与前中心小尖有愈 合的趋势, 后壁发育了釉质褶曲; 副齿柱大部分破损, 从外轮廓看, 其主尖粗壮, 中附雉较之为细, 后中心 小尖发育; 后方舌侧齿谷在边缘有一粗壮的乳突及 若干小乳突发育, 唇侧齿谷中还有一粗壮的乳突及 一些稍小的乳突发育. 第二脊磨耗较轻, 主齿柱的中 附雉不能确切分辨是与前中心小尖还是后中心小尖 愈合, 侧壁发育了釉质褶曲; 副齿柱主尖粗壮, 中附 雉横长, 略磨耗后呈葫芦形, 向前方近轴侧倾斜, 后 中心小尖发育, 后壁的釉质层褶曲不强烈; 后方舌侧 齿谷的边缘有一粗壮的乳突发育, 唇侧齿谷窄小. 第 三脊磨耗轻微, 主齿柱的主尖很粗壮, 侧壁和后壁釉 质层发育了褶曲, 中附雉与前中心小尖融合, 两者均 很粗壮, 前方发育锯齿嵴与前一脊副齿柱的后中心 小尖联系; 副齿柱的主尖粗壮, 中附雉稍弱, 主副齿 柱的半个齿脊均强烈向前方近轴侧倾斜. 从第三脊 主齿柱的后中心小尖向后侧弧形排列有三个大的乳 突组成了跟座, 高度逐渐降低. 齿带在前方发育强, 第一脊主齿柱的舌侧有一些大小不规则的乳突环绕 形成明显的齿带, 向后齿带发育变弱, 唇侧的齿带更 不发育; 白严质发育弱. 右侧 M2 的结构与左侧类似, 前端有破损.

左侧的 M3 已经完全从上领突中推出, 呈前宽后 窄的长三角形, 由三脊及一跟座组成, 完全没有磨耗. 第二和三脊呈尖点向前的 $\mathrm{V}$ 形, 整个冠面呈现出较 明显的豕脊型齿和弱的褶型齿. 第一脊主齿柱的主 尖粗壮而高䇯, 前中心小尖也很粗壮, 其后侧近轴方 向愈合有一薄片状的乳突, 并不与主尖相连, 可能是 中附雉. 前中心小尖向前与前齿带相连, 后中心小尖 粗壮, 侧壁发育了较弱的褶曲; 副齿柱的主尖与中附 雉接近愈合, 各自在顶部分裂成两个小乳突, 副齿柱 与薄片状的主齿柱中附雉相连, 后中心小尖较发育, 后壁的釉质层褶曲不明显; 第一脊后方齿谷相对光 滑, 没有明显的乳突发育. 第二脊与第一脊类似, 主 齿柱的中附雉与前中心小尖愈合, 形成向前的锯齿 嵴, 后中心小尖不发育, 侧壁发育了较弱的褶曲; 副 齿柱略向前方近轴侧倾斜, 主尖与中附雉趋于愈合, 各自在顶部分裂成一些小乳突, 后中心小尖较弱; 后 方舌侧齿谷边缘处发育了一个强大的乳突, 唇侧齿
谷比较光滑. 第三脊与前两脊相似, 但宽度窄, 冠高 小, 主齿柱主尖较粗壮, 中附雉与前中心小尖愈合成 的锯齿嵴很发育, 但后中心小尖不发育; 副齿柱则与 前一脊基本相同. 跟座主齿柱的两个乳突与副齿柱 的两个乳突均向近轴侧倾斜排列, 形成一个尖点向 前的 $\mathrm{V}$ 形, 在 $\mathrm{V}$ 形的后部开口处则发育有一个小乳 突封闭开口, 整个跟座形成一簇环形的锥簇. 齿带在 前端很发育, 在舌侧转向后方, 到第一脊的齿谷边缘 都很发育, 向后则发育变弱, 唇侧的齿带更不发育; 白垩质发育弱. 右侧的 M3 跟座还埋在上领突中, 其 前三脊的结构与左侧大致相同.

\section{2 对比讨论}

豕脊齿象是 Schlesinger ${ }^{[10]}$ 依据希腊匹克米 (Pikermi)晚中新世的 Mastodon pentelici Gaudry et Lartet, 1856 的材料提出的分类单元; Gaziry ${ }^{[11]}$ 建立了 豕脊齿象亚科, 仅包括豕脊齿象一属. 除了属型种 Choerolophodon pentelici, 豕脊齿象属还包括 $\mathrm{Ch}$. palaeindicus Lydekker, 1884, Ch. pygmaeus Depéret, 1897, Ch. corrugatus Pilgrim, 1913, Ch. kisumuensis MacInnes, 1942, Ch. ngorora Maglio, 1974, Ch. chioticus Tobien, 1980 和 Ch. zaltaniensis Gaziry, 1987; 主要分布在中新世的东欧、西亚、南亚和非洲 ${ }^{[11 ~ 18]}$. Pickford ${ }^{[13,19]}$ 将 Ch. kisumuensis 和 Ch. chioticus 改定 为非洲豕齿象属(Afrochoerodon), 仍然属于豕脊齿象 亚科. Sanders 和 Miller ${ }^{[20]}$ 认为 Ch. palaeindicus 可能属 于非洲豕齿象属.

在中国有周明镇和张玉萍 ${ }^{[21]}$ 报道过厚齿象属 (Synconolophus, 根据 Tassy ${ }^{[22]}$ 的意见作为 Choerolophodon 的同物异名看待)的两个种 S. fukienensis Zhou et Zhang, 1974, S. cf. ptychodus Osborn, 1951 及 一个未定种, 时代是晚中新世或上新世, 地点均在中 国南方. 这些材料均为孤立的臼齿, 可能与西瓦立克 晚中新世的 Ch. corrugatus 有直接关系. Tobien 等 ${ }^{[7]}$ 将中国的材料中一些曾定为嵌齿象属(即三棱齿象属 Trilophodon)或铲齿象属的材料归入豕脊齿象属未定 种, 包括以下一些材料: 1) TM-18 902, 左 M1, 原定 为 $T r$. cf. wimani; 2) TM-18 899, 右 M2, 原定为 $T r$. wimani; 3) GM-Vm 503, 右 $\mathrm{m} 3$ (或 $\mathrm{m} 2$ )残段, 原定为 Gomphotherium elegans; 4) IVPP V2565, 左 M1, 原 定为 G. cf. connexus; 5) IVPP V2680, 左 M3 残段, 原 
定为 G. changzhiensis; 6) IVPP V3083, m3 残段, 原定 为 Platybelodon grangeri; 7) IVPP V5576, 右 M1, 原 定为 Pl. grangeri. 这些材料均为一些孤立的项齿, 归 为豕脊齿象属并不可靠, 例如陈冠芳 [23] 就认为 1 ) 和 2)这两个材料应归入中华乳齿象属(Sinomastodon).

Schlesinger ${ }^{[10]}$ 给出的豕脊齿象的鉴定特征为: 头骨低, 前后延伸; 门齿向外侧及上方弯曲, 没有釉 质带; 下领中等伸长, 下门齿缺失; 自齿为豕脊型齿. 大浪沟的材料除了缺少下领外, 头骨、上门齿和上白 齿的特征均符合这些鉴定特征. 门齿向上方弯曲并 且没有釉质带足以使大浪沟的材料与嵌齿象属 (Gomphotherium)、铲齿象属(Platybelodon)和轭齿象 属(Zygolophodon)等相区别, 而头骨低平及豕脊型齿 亦与中华乳齿象属 (Sinomastodon) 和互棱齿象属 (Anancus) 等区别, 因此, 大浪沟的材料无疑应归入 豕脊齿象属.

Tassy ${ }^{[8]}$ 修定的豕脊齿象属的鉴定特征有：1）颖 部窄, 拱形的歡弓与脑颖靠近；2) 面颊相对于脑颖 很发育；3）腭部后缘延伸到颊齿列之后；4）眼眭和 外鼻孔后退到颊齿列之后, 眶题嵴近坚直; 5) 下领 联合部的槽大而深；6）上门齿朝上弯，釉质带缺失; 7) 下门齿缺失; 8) 缺少 $\mathrm{dp} 2, \mathrm{P} 2, \mathrm{P} 3, \mathrm{p} 3, \mathrm{P} 4$ 和 $\mathrm{p} 4$ 等规 齿;9) dp3 主齿柱的中附雉与后尖联接; 10) 兒齿为豕 脊型齿: 中附雉与前中心小尖高且大, 相互紧密联接 或愈合, 位于牙齿的长轴方向, 从而齿脊形成尖点向 前的 V 形. 除了无法观察的 5), 7) 和 9) 点外, 2), 3), 6) 和 10)点完全附合我们的标本; 1), 4)和 8)三点有所不 同: 大浪沟的材料的歡弓向外较为扩展, 眼眭与鼻孔 位置靠前, P4 仍然保存, 这些恰恰是大浪沟材料具有 的原始特征.

Schlesinger ${ }^{[10]}$ 描述了匹克米晚中新世的豕脊齿 象属型种 Choerolophodon pentelici 的 3 个幼年的头骨; Gaziry $^{[11]}$ 描述了土耳其晚中新世 Ch. pentelici 的材料, 包括完整的头骨. 与大浪沟的材料相比, 两者除了具 有豕脊齿象属的共同特征之外, 还有许多不同: Ch. pentelici 的顶骨的顶面非常宽阔，几乎与额骨顶面等 宽, 脑妙顶面后缘较平直, 题窝长度较小; 㩲弓及外 枕骨向外扩张的程度弱, 基枕骨较长; 项韧带窝较小, 呈圆形; 外鼻孔较窄, 门齿窝之后的凸棱位于鼻尖之 前; Ch. pentelici 的眼眶前缘退缩到齿列之后, 并位于 头骨侧面的顶部, 这显然是一种非常特化的特征. 此 外, Ch. pentelici 的门齿向上弯曲的程度较大; 项齿的
豕脊型特征发育更强，白严质更发育，尺寸比大浪沟 的材料稍大(图 7).

南亚西瓦立克地区中中新世到晚中新世 Choerolophodon corrugatus 的材料与大浪沟的材料有较明 显的不同 ${ }^{[15]}$. Ch. corrugatus 的尺寸大(图 7), M3 的长 度一般在 $160 \mathrm{~mm}$ 以上, $\mathrm{M} 2$ 的长度一般在 $110 \mathrm{~mm}$ 以 上，远大于大浪沟的材料，并且 Ch. corrugatus 的 M3 趋向于四脊加一跟座. Ch. corrugatus 的眼眭退缩到 齿列之后, 上领骨相当高, 颖基部与腭部并非接近水 平, 而是有相当大的倾角; 颊齿的豕脊型特征及釉质 褶曲发育更强，白严质相当发育。而西瓦立克早中新 世到中中新世 Kamlial 组的 Choerolophodon sp. 的材 料仅为孤立的颊齿, 其 M3 有四脊, 尺寸也较大浪沟 的材料稍大 ${ }^{[16]}$, 可能与 Ch. corrugatus 有一定关系.

非洲晚中新世 Choerolophodon ngorora 的正型标 本为一件带 M2 M3 齿列的残破上领, 发现于肯尼亚 Ngorora 组的 E 段(位于该组顶部) ${ }^{[24]}$. Pickford ${ }^{[13]}$ 将 Ngorora 组中归入该种的其他年代更早的标本改定为 非洲豕齿象属, 仅将 Ngorora 组 E 段的材料保留在该 种中. 与大浪沟材料所不同的是, Ch. ngorora 的颊齿 尺寸较大(图 7), M3 的第四脊已完全形成, 齿脊前后 向压缩, 齿谷较宽, 釉质褶曲强烈, 白严质很发 育 $^{[24]}$.

事实上，大浪沟的材料有 4 个明显的原始特征: 歡弓明显向两侧扩展、眼眀位置靠前、P4 仍然发育 和顿齿上白垩质发育很弱. 这 4 点足以将大浪沟的材 料与以上豕脊齿象属晚中新世的各种区分开(前两点 头骨特征在 Ch. ngorora 中仍然未知).

Depéret ${ }^{[26]}$ 描述了阿尔及利亚卡拜里(Kabylie)一 件残破的嵌齿象类的 $\mathrm{m} 3$, 当时定名为 Mastodon angustidens pygmaeus, 该规齿第一脊缺失, 仅剩三脊, 表面覆盖着很厚的白严质. 这件孤立标本的归属长 期引起了很大的争议. Pickford ${ }^{[13]}$ 描述了发现于肯尼 亚 Ngorora 组 A 段(位于该组底部, 中中新世, 约 13 $\mathrm{Ma})$ 的嵌齿象类材料, 包括上下齿列, 残破门齿及部 分头后骨骼. Pickford ${ }^{[13]}$ 认为这些材料中的 $\mathrm{m} 3$ 与 Depéret ${ }^{[26]}$ 描述的 $\mathrm{m} 3$ 十分接近, 并且具有典型的豕脊 齿象属的特征, 因此将这些材料归为 Choerolophodon pygmaeus; 此外, 在南非和纳米比亚也发现了 Ch. pygmaeus 的材料 ${ }^{[14]}$. Ch. pygmaeus 是一种小型化 的豕脊齿象，颊齿尺寸小于大浪沟的材料(图 7); 然 而其 M3 的第四脊发育完好, 其后形成了一个跟座, 

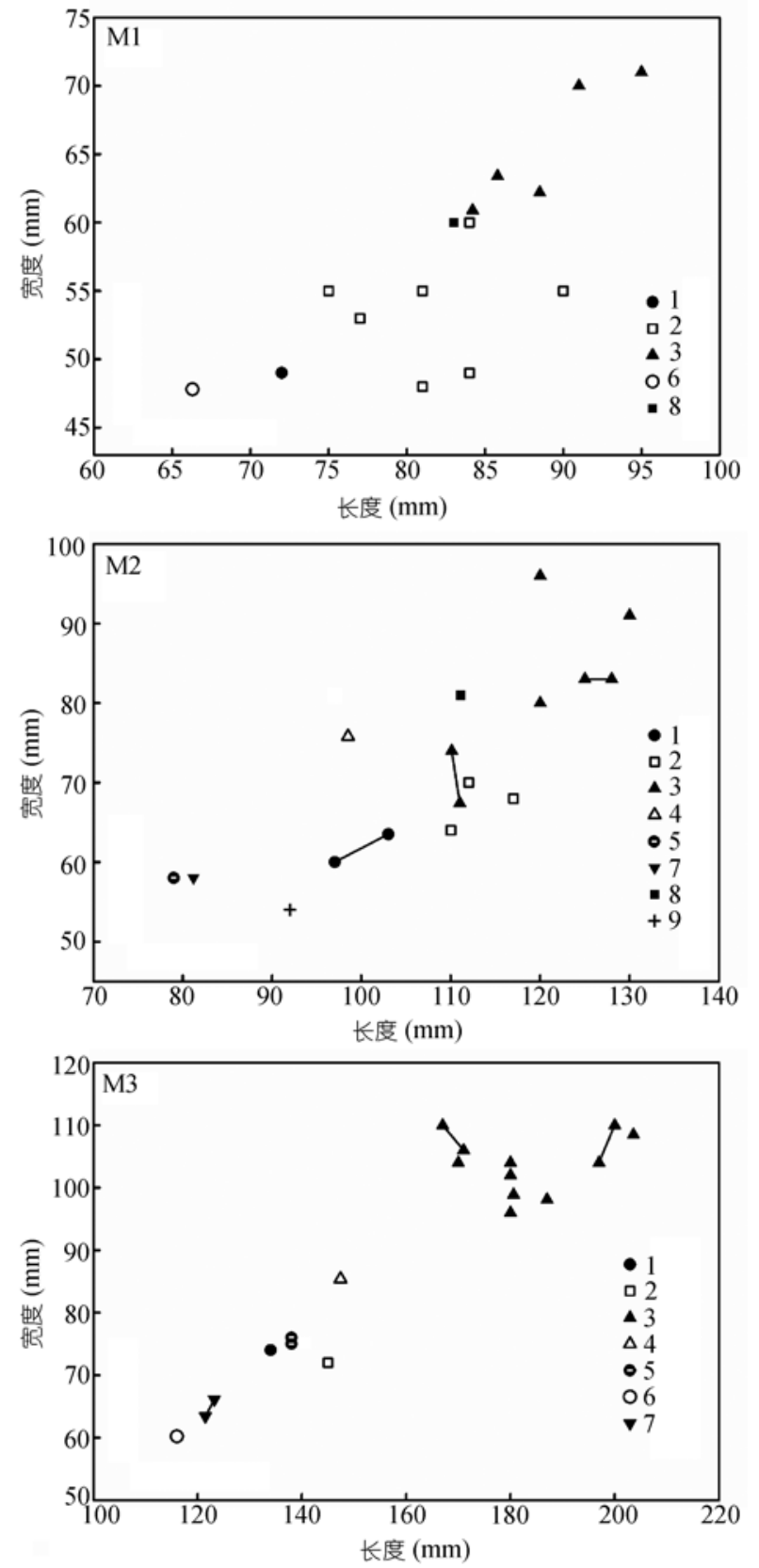

图 7 豕脊齿象亚科项齿测量比较

1, Choerolophodon guangheensis ep. nov.; 2, Choerolophodon pentelici, 数据来源于文献[11]; 3 , Ch. corrugatus, 数据来源于文献 [15]; 4, Ch. ngorora，数据来源于文献[24]; 5, Ch. zaltaniensis, 数据 来源于文献[12]; 6, Ch. pygmaeus, 数据来源于文献[13]; 7, Afrochoerodon kisumuensis, 数据来源于文献[19]; 8, Af. chioticus, 数 据来源于文献[18]; 9, Ch. palaeindicus, 数据来源于文献[25]. 横线 相连的两个数据代表同一个体

齿脊相对前后压缩, 齿谷较宽, 颊齿白严质较发育, 这些特征均较大浪沟的材料进步.
Gaziry $^{[12]}$ 依据利比亚 Jabal Zaltan 晚中新世的一 些颊齿及残破下领材料建立了 Choerolophodon zaltaniensis. 该种 M3 的大小与大浪沟的材料很接近 (图 7); 然而，该种 M3 的第四脊发育完好，颊齿的釉 质褶曲及白严质均较为发育, 性质与 Ch. pygmaeus 相似. Pickford ${ }^{[13]}$ 推测, Ch. zaltaniensis 是 Ch. pygmaeus 的同物异名，两者之间的大小差异仅由性 别差异引起，但没有更多的材料支持这一推测. 无论 如何, Ch. zaltaniensis 的颊齿所表现的特征比大浪沟 的材料显得更加进步.

Pickford $^{[19]}$ 依据肯尼亚 Cheparawa 中中新世 Muruyur 组(约 $15 \mathrm{Ma}$ )的材料建立了非洲豕齿象属 (Afrochoerodon), 他认为新材料与原定为 Choerolophodon kisumuensis 的材料非常接近, 因此将 Ch. kisumuensis 改定为 Af. kisumuensis 并作为属型种, 并 且希腊爱琴海希俄斯(Chios)岛的 Ch. chioticus Tobien, 1980 的材料归入新属 ${ }^{[13,19]}$. Pickford ${ }^{[19]}$ 认为非洲豕齿 象属和豕脊齿象属属于两个不同的分支, 因为非洲 豕齿象属具有显著倾斜下降的面部，在炒顶处十分 靠近的额线, 相对高而短的脑频部, 相对收缩的频基 部, 并且其下㚘齿的主齿柱偏向唇侧, 因此显著区别 于豕脊齿象属. 由于非洲豕齿象属牙齿的豕脊型齿 特征较弱, 门齿发育有釉质带的残余, 因此比豕脊齿 象属更加原始.

大浪沟的材料同样具有较多的原始特征, 如, 白 严质不发达, 齿脊上的齿雉较钝圆. 然而其头骨低平 且前后延伸, 题线在顶骨顶面的间距较宽, 面部低且 较水平, 齿槽略微下倾, 与 Afrochoerodon kisumuensis 显著不同，其軑齿略大于 Af. kisumuensis (图 7); 类似的区别也见于 Af. chioticus $^{[18]}$, 只不过大浪沟材 料的颊齿较小(图 7). 由于以上不同之处(除了颊齿的 不同)均属于豕脊齿象属区别于非洲豕齿象属的共衍 征，因此，大浪沟的标本更可能归入豕脊齿象属而不 是非洲豕齿象属.

巴基斯坦德拉布提(Dera Bugti)早中新世 Choerolophodon palaeindicus 的材料仅为一个 $\mathrm{m} 3$ 和一个磨 耗非常深的 $\mathrm{M} 2^{[25]}$. 其 $\mathrm{M} 2$ 的尺寸与大浪沟的材料接 近(图 7), 其 $m 3$ 明显是豕脊型齿，但釉质褶曲及白严 质发育很弱，与大浪沟的材料有一定的相似性(虽然 无法直接比较). Sanders 和 Miller ${ }^{[20]}$ 认为 $C h$. palaeindicus 可能属于非洲豕齿象属, 理由仅仅是其 
结构原始, 与 Afrochoerodon kisumuensis 接近. 事实 上Ch. palaeindicus 这个种定名所依据的材料过于狭 窄, 其性质相当模糊, 只能泛泛地推测, 有可能大浪 沟的材料与 Ch. palaeindicus 有一定的亲缘关系.

由于 Choerolophodon pygmaeus 的确立, Pic$\mathrm{kford}^{[13]}$ 认为豕脊齿象属可能起源于中中新世的非洲, 在晚中新世迁移到欧亚大陆; 而他将其定为豕脊齿 象属时主要的依据是其颊齿的豕脊型齿、釉质褶曲和 白严质均发育较强. 但是这些特征可能是后期的豕 脊齿象亚科成员的共近裔特征, 头骨的形态却因为 没有发现材料而无法确认, 头骨的特征是区分这两 属的更本质的特征. Pickford ${ }^{[13]}$ 在讨论豕脊齿象属在 晚中新世从非洲向欧亚大陆迁移时, 并未讨论南亚 的 Ch. palaeindicus, 可能他也认为 Ch. palaeindicus 应当属于非洲豕齿象属. 然而大浪沟材料低平的头 骨, 却明显与非洲豕齿象属的属型种 Afrochoerodon kisum- uensis 不同. 虽然无法给出一个直接的判定, 大浪沟地点的时代据我们估计不晚于 $16 \mathrm{Ma}$, 比 $C h$. pygmaeus 的地点要早. 因此, 大浪沟材料的发现与 Pickford 关于豕脊齿象属起源和迁移的假设并不一致, 如果大浪沟的材料确实可归入豕脊齿象属, 那么其 更有可能接近于豕脊齿象属的祖先类型, 因此, 豕脊 齿象属的起源至少要上推至早中新世, 起源地点是 非洲还是欧亚大陆仍然是一个迷.

\section{3 总结}

本文记述的广河豕脊齿象(新种)化石发现于大 浪沟早中新世上庄组, 其时代远早于非洲发现 Choerolophodon pygmaeus 的 Ngorora 组的 A 段(中中 新世 ${ }^{[13]}$ ). 与此对应, 广河豕脊齿象 (新种)具有一些 相当原始的特征, 如歡弓明显向两侧扩展、眼睈位置 靠前、保存 P4、颊齿白严质发育很弱. 而且早中新世 中国的嵌齿象类材料发现很少, 豕脊齿象类的材料 在中国报道也很少. 因此, 大浪沟材料的发现证明, 早在早中新世的晚期, 豕脊齿象类已经深入到中国 的北方地区, 这不仅是对早中新世中国嵌齿象类化 石记录的完善, 同时对于研究豕脊齿象属的起源和 演化以及嵌齿象类在东亚地区的适应辐射有相当重 要的意义. 此外, 有观点认为豕脊齿象属是属于半水 栖的类型, 尤其是 Ch. pentelici (由于其头骨扁平, 眼 睈位置较高 ${ }^{[14]}$ ), 而大浪沟的广河豕脊齿象(新种)的 头骨虽然眼眭位置不高, 但也相当扁平, 推测其也可 能具有近水的生活习性; Deng ${ }^{[27]}$ 记述了同一地点的 巨獠犀未定种(Aprotodon sp.), 巨獠犀也被认为具有 与河马相似的形态特征和生活习性 ${ }^{[27,28]}$, 因此可以 推测, 大浪沟地区当时的生态环境应该是相当湿润, 具有丰富的河流和湖泊. 这对于恢复临夏盆地早中 新世的古环境有一定的参考价值.

致谢本工作的完成得益于邱占祥、陈冠芳、叶捷和王元等的指导和讨论, 法国巴黎自然博物馆的 Pascal Tassy 和 Martin Pickford 提供文献, 甘肃和政古动物化石博物馆的何文和陈善勤整理广河豕脊齿象(新种)的材料, 王 宁和赵敏拍照，时福桥和吴胜利修理部分化石，在此一并表达诚挚的谢意. 同时，作者对诸审阅人的辛勤工 作表示衰心的感谢.

\section{参考文献}

1 Shoshani J, Tassy P. Advances in proboscidean taxonomy \& classification, anatomy \& physiology, and ecology \& behavior. Quat Int, 2005, 126-128: 5-20

2 Tobien H. On the evolution of mastodonts (Proboscidea, Mammalia). Part 1: The bunodont trilophodont groups. Notizbl Hess L-Amt Bodenforsch, 1973, 101: 202-276

3 Tassy P. The earliest gomphotheres. In: Shoshani J, Tassy P, eds. The Proboscidea: Evolution and Palaeoecology of Elephants and Their Relatives. Oxford, New York, Tokyo: Oxford University Press, 1996. 89-91

4 Lambert W D. The biogeography of the gomphotheriid proboscideans of North America. In: Shoshani J, Tassy P, eds. The Proboscidea: Evolution and Palaeoecology of Elephants and Their Relatives. Oxford, New York, Tokyo: Oxford University Press, 1996. 143-148

5 王伴月, 邱占祥. 铲齿象一新种在甘肃省党河地区下中新统的发现. 古脊椎动物学报, 2002, 40: 291-299

6 王伴月, 邱占祥, 王晓鸣, 等. 甘肃省党河地区的新生代地层和青藏高原隆升. 古脊椎动物学报, 2003, 41: 66-75

7 Tobien H, Chen G F, Li Y Q. Mastodonts (Proboscidea, Mammalia) from the late Neogene and early Pleistocene of the People's Republic of China. Part I: Historical account: The genera Gomphotherium, Choerolophodon, Synconolophus, Amebelodon, Platybelodon, 
Sinomastodon. Mainz Geowiss Mitt, 1986, 15: 119-181

8 Tassy P. Les Elephantoidea Miocènes du Plateau du Potwar, Groups de Siwalik, Pakistan. ${ }^{\text {re }}$ partie: cadre chronologique et géographique, mammutidés, amébélodontidés. Ann Paléontol, 1983, 69: 99-136

9 Tassy P, Pickford M. Un nouveau mastodonte zygolophodonte (Proboscidea, Mammalia) dans le Miocène inférieur d'Afrique orientale: Systématique et paléoenvironnement. Géobios, 1983, 16: 53-77

10 Schlesinger G. Die mastodonten des K. K. naturhistorischen Hofmuseums. Denkschr K K Naturhist Hofm, Geol-paläont, 1917, 1: 181-222

11 Gaziry A W. Jungtertiäre mastodonten aus Anatolien (Türkei). Geol Jb, 1976, B22: 3-143

12 Gaziry A W. New mammals from the Jabal Zaltan site, Libya. Senckenb Leth, 1987, 68: 69-89

13 Pickford M. Partial dentition and skeleton of Choerolophodon pygmaeus (Depéret) from Ngenyin, 13 Ma, Tugen Hills, Kenya: Resolution of a century old enigma. Zona Arqueologica: Miscelànea en Homenaje a Emiliano Aguirre. Paleontologia, 2004, 4: 428-463

14 Pickford M. Choerolophodon pygmaeus (Proboscidea Mammalia) from the middle Miocene of southern Africa. S Afr J Sci, 2005, 101: $175-177$

15 Tassy P. Les Elephantoidea Miocènes du Plateau du Potwar, Groups de Siwalik, Pakistan. II $^{\mathrm{e}}$ partie: choerolophodontes et gomphothères. Ann Paléontol, 1983, 69: 235-297

16 Tassy P. Nouveaux Elephantoidea (Proboscidea, Mammalia) dans le Miocène du Kenya: Essai de réévaluation systématique. Paris: Cahiers de Paléontologie. E'ditions du Centre National de la Recherche Scientifique, (CNRS), 1986, 56: 65-79

17 Tassy P. Proboscideans (Mammalia) from the late Miocene of Akkaşdağ, Turkey. Geodiversitas, 2005, 27: 707-714

18 Tobien H. A note on the skull and mandible of a new choerolophodont mastodont (Proboscidea, Mammalia) from the middle Miocene of Chios (Aegean Sea, Greece). In: Jacobs L, ed. Aspects of Vertebrate History: Essays in Honor of Edwin Harris Colbert. Flagstaff: Museum of Arizona Press, 1980. 299-307

19 Pickford M. Afrochoerodon nov. gen. kisumuensis (MacInnes) (Proboscidea, Mammalia) from Cheparawa, middle Miocene, Kenya. Ann Paléontol, 2001, 87: 99-117

20 Sanders W J, Miller E R. New proboscideans from the early Miocene of Wadi Moghara, Egypt. J Vert Paleontol, 2002, 22: 388-404

21 周明镇, 张玉萍. 中国的象化石. 北京: 科学出版社, 1974. 31-32

22 Tassy P. Who is who among the Proboscidea. In: Shoshani J, Tassy P, eds. Evolution and Palaeoecology of Elephants and Their Relatives. Oxford, New York, Tokyo: Oxford University Press, 1996. 39-48

23 陈冠芳. 中国上新世和更新世早、中期的中华乳齿象. 见: 王元青, 邓涛, 编. 第七届中国古脊椎动物学学术年会论文集. 北京: 海 洋出版社, 1999. 179-187

24 Maglio V J. A new proboscidean from the late Miocene of Kenya. Palaeontology, 1974, 17: 699-705

25 Osborn H F. Proboscidea: A Monograph of the Discovery, Evolution, Migration and Extinction of the Mastodonts and Elephants of the World. Volume I: Moeritherioidea, Deinotherioidea, and Mastodontoidea. New York: The American Museum Press, 1936. 268

26 Depéret C. Découverte du Mastodon angustidens dans l'étage cartennein de Kabylie. Bull Soc Géol Fr, 1897, 3: 518-521

27 Deng T. Neogene rhinoceroses of the Linxia Basin (Gansu, China). Cour Forsch-Inst Senckenberg, 2006, 256: 43-56

28 邓涛. 临夏盆地晚新生代哺乳动物群演替与青藏高原隆升背景. 第四纪研究, 2004, 24: 413-420 

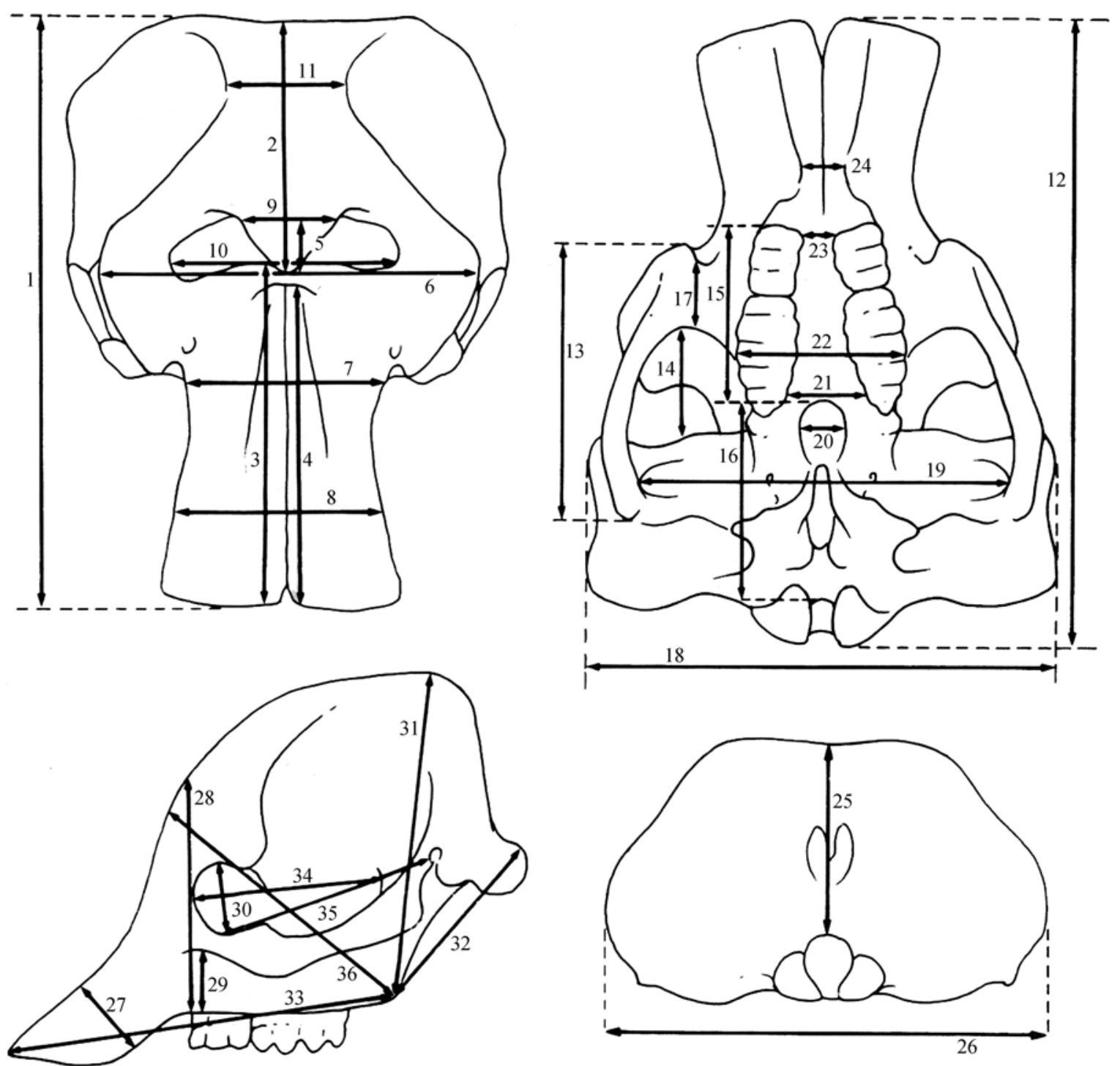

附图 1 嵌齿象类头骨测量

引自文献[8]中的图 5.1, 从枕骨边测量的最大长度; 2 , 脑顽长度; 3 , 前领骨长度 $; 4$, 门齿窝长度; 5 , 鼻骨长度; 6 , 最大眶上宽度; 7, 吻部后宽 (在下眀下孔间测量); 8 , 吻部前宽; 9 , 鼻骨宽度; 10 , 外鼻孔宽度; 11 , 脑㐿题线间最小宽度 $; 12$, 从枕髁测量的最大长度; 13 , 鹳弓长度(从上 领歡突前到关节窝后缘); 14 , 从歡弓水平面上测量题窝长度; 15, 硬腭长度(从第一个颊齿到内鼻孔); 16, 内鼻孔到枕大孔的长度; 17 , 上领歡 突厚度; 18 , 脑㐿最大宽度 (从两颧弓上测量); 19 , 颅基宽度(从两关节窝的外缘测量); 20, 内鼻孔最大宽度; 21, 硬腭内部最大宽度; 22, 硬腭 外部最大宽度; 23 , 硬腭内部在第一颊齿前端的宽度; 24 , 硬腭最小宽度，在内齿槽脊(上领脊)间测量; 25 , 枕骨矢向高度; 26 , 枕骨宽度; 27 ,

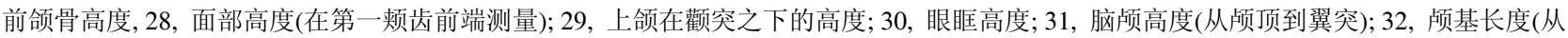
翼突到枕髁); 33, 面部长(从吻部前端到翼突); 34, 眶额窝长(从鳞骨前缘到眼眀前缘); 35，颅中部长(从眼眭下缘到外耳道开口); 36, 颅中部 高(从翼突到眼眶背缘) 


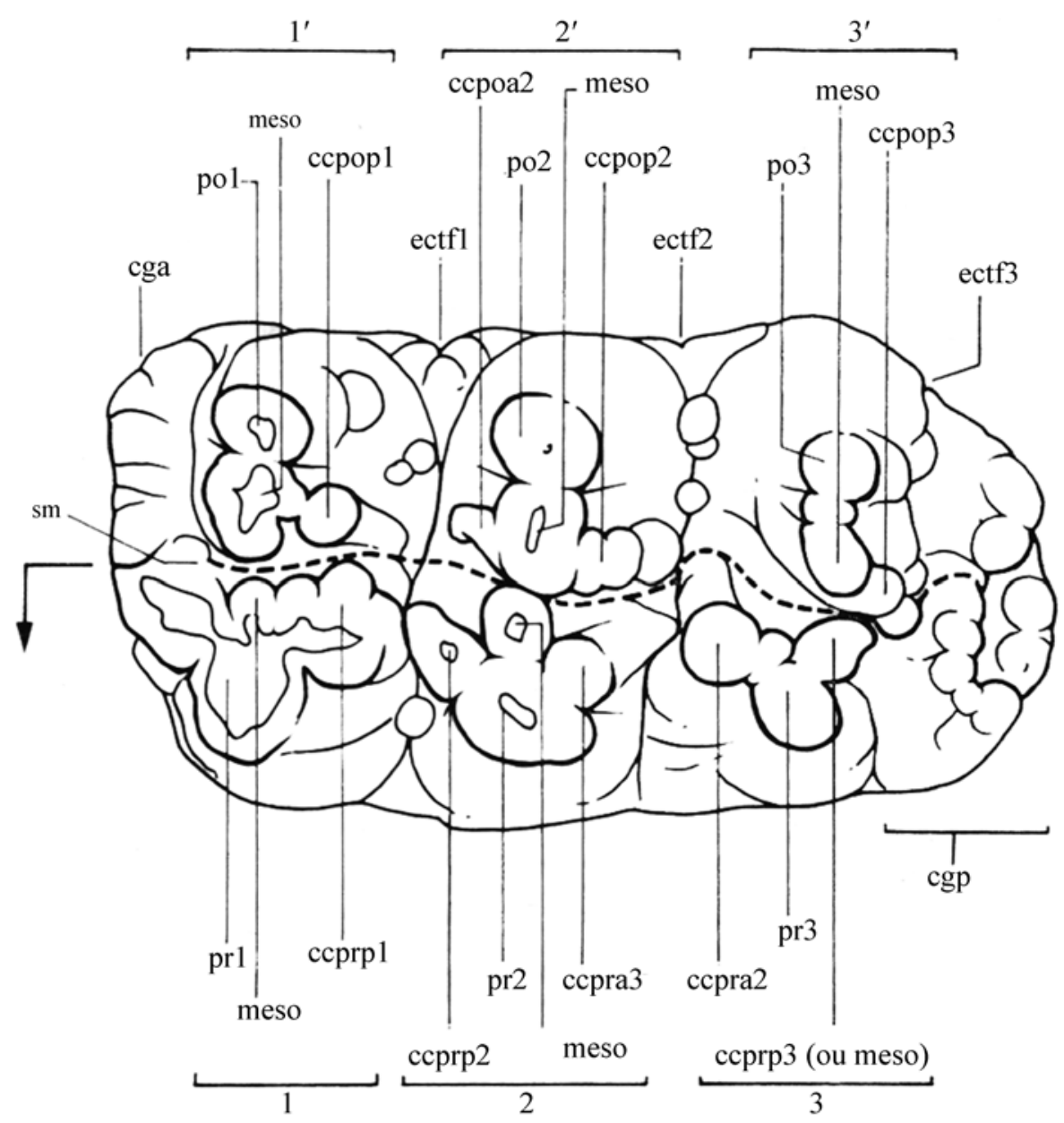

附图 2 嵌齿象类(Protanancus chijiensis 左 M2)项齿冠面描述术语

引自文献[8]中的图 4. 1, 2, 3: 第 1,2,3 脊主齿柱; $1^{\prime}, 2^{\prime}, 3^{\prime}$ : 第 1,2,3 脊副齿柱; ccpoa2: 第 2 脊副齿柱前中心小尖; ccpop1, ccpop2, ccpop3: 第 1,2,3 脊副齿柱后中心小尖; ccpra1, ccpra2, ccpra3: 第 1, 2, 3 脊主齿柱前中心小尖; ccprp1, ccprp2, ccprp3: 第 1, 2, 3 脊主齿柱后中心小尖; cga, 前齿带; cgp, 后齿带; ectf1, ectf2, ectf3: 第 1,2, 3 外谷; meso, 每脊主齿柱或副齿柱的中附雉; po1, po2, po3: 第 1, 2, 3 脊副齿柱主尖; pr1, pr2, pr3: 第 1,2, 3 脊主齿柱主尖; sm: 中沟 